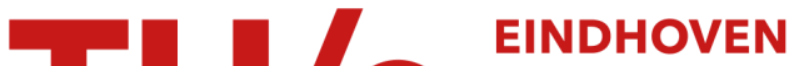 UNIVERSITY OF TECHNOLOGY
}

\section{Minimising rotor losses in high-speed high-power permanent magnet synchronous generators with rectifier load}

\section{Citation for published version (APA):}

Veen, van der, J. L. F., Offringa, L. J. J., \& Vandenput, A. J. A. (1997). Minimising rotor losses in high-speed high-power permanent magnet synchronous generators with rectifier load. IEE Proceedings - Electric Power Applications, 144, 331-337. https://doi.org/10.1049/ip-epa:19971354

DOI:

10.1049/ip-epa:19971354

Document status and date:

Published: 01/01/1997

\section{Document Version:}

Publisher's PDF, also known as Version of Record (includes final page, issue and volume numbers)

\section{Please check the document version of this publication:}

- A submitted manuscript is the version of the article upon submission and before peer-review. There can be important differences between the submitted version and the official published version of record. People interested in the research are advised to contact the author for the final version of the publication, or visit the $\mathrm{DOI}$ to the publisher's website.

- The final author version and the galley proof are versions of the publication after peer review.

- The final published version features the final layout of the paper including the volume, issue and page numbers.

Link to publication

\section{General rights}

Copyright and moral rights for the publications made accessible in the public portal are retained by the authors and/or other copyright owners and it is a condition of accessing publications that users recognise and abide by the legal requirements associated with these rights.

- Users may download and print one copy of any publication from the public portal for the purpose of private study or research.

- You may not further distribute the material or use it for any profit-making activity or commercial gain

- You may freely distribute the URL identifying the publication in the public portal.

If the publication is distributed under the terms of Article 25fa of the Dutch Copyright Act, indicated by the "Taverne" license above, please follow below link for the End User Agreement:

www.tue.nl/taverne

Take down policy

If you believe that this document breaches copyright please contact us at:

openaccess@tue.nl

providing details and we will investigate your claim. 


\title{
Minimising rotor losses in high-speed high-power permanent magnet synchronous generators with rectifier load
}

\author{
J.L.F.van der Veen \\ L.J.J.Offringa \\ A.J.A. Vandenput
}

Indexing terms: Synchronous generators, Rotor losses, Permanent magnet generators, Stator winding configurations

\begin{abstract}
In an early stage of the design of a high-speed $1400 \mathrm{~kW}$ synchronous generator with permanent magnet excitation and loaded by a rectifier, it became apparent that rotor losses are a major problem. The stator currents cause asynchronous components in the air-gap field. Analysis shows that a modified polyphase system reduces the number of these components. An approximate solution for the rotor losses caused by the asynchronous field components has been derived. The formulae show the effects of machine dimensions and harmonics and the effect of a conducting shield in the rotor. The main purpose of the study is to have a tool for making an early choice among several stator winding configurations. A modified nine-phase system, combined with a shield around the permanent magnet rotor, is a prospective option.
\end{abstract}

\section{List of symbols}

$A_{n q} \quad=$ surface current density due to the $n$th current harmonic and the $q$ th space harmonic

$A_{r g}=$ surface current density on the conducting shield with radius $r_{g}$

$A_{3} \quad=$ surface current density at the stator bore

$B_{r}, B_{\theta}=$ radial, tangential component of the magnetic induction

$B_{2} \quad=$ radial component of the magnetic induction at radius $r_{2}$

$d \quad=$ thickness of the conducting shield

$d_{\text {skin }}=$ skin depth

$E_{2} \quad$ = axial component of the electric field strength at radius $r_{2}$

$h_{m} \quad=$ height of the permanent magnets

$i, j \quad=$ integers

$I_{d c} \quad=$ DC current

(C) IEE, 1997

IEE Proceedings online no. 19971354

Paper first received 15th November 1996 and in final revised form 24th March 1997

The authors are. with Eindhoven University of Technology, Department of Electrical Engineering, Electromagnetics and Power Electronics Group, Eindhoven, The Netherlands
$I_{n} \quad=n$th harmonic component in the phase current

$J_{r g} \quad=$ volume current density in the conducting layer

$k=$ number of subsystems in the stator

$k_{1}, k_{2}, k_{3}=$ integers

$l=$ active length of the machine

$n \quad=$ order of the harmonic in the current

$N_{s} \quad=$ number of stator slots

$p \quad=$ pole pair number

$p q=$ absolute order of the space harmonic

$P_{r g} \quad=$ rotor losses due to one asynchronous component

$P_{r} \quad=$ total rotor losses

$q \quad=$ relative order of the space harmonic

$Q_{s, n, q}=$ quality factor for the component with order $n$ and $q$

$r \quad=$ radial co-ordinate

$r_{0} \quad=$ reference radius

$r_{g} \quad=$ radius of the conducting layer in the rotor

$r_{1} \quad=$ radius of the solid rotor iron

$r_{2}=$ radius of the conducting shield

$r_{3}=$ radius of the stator bore

$t \quad=$ time

$Z_{q} \quad=$ winding distribution density of the $q$ th harmonic

$m \quad=$ commutation interval

$\mu_{0} \quad=$ permeability of vacuum

$\sigma \quad=$ specific conductivity

$\theta_{r} \quad=$ tangential co-ordinate in rotor co-ordinates

$\theta_{s}=$ tangential co-ordinate in stator co-ordinates

$\omega_{m} \quad=$ mechanical angular velocity of the rotor

$\omega_{r} \quad=$ electric angular frequency in rotor coordinates

$\omega_{s} \quad=$ fundamental frequency of the stator current

\section{Introduction}

The application of a high-speed generator with permanent magnet excitation in a gas turbine-generator set has potential advantages. The solid and simple con- 
struction enables operation at high speed and a direct coupling of the turbine with the generator. The important features of such a unit are small volume, low weight and high efficiency.

In the framework of a NOVEM project $[1,2]$ a design of a $1400 \mathrm{~kW}, 18000 \mathrm{rpm}$ synchronous generator has been made. The output voltage with a frequency of $600 \mathrm{~Hz}$ will be rectified. The generator is of the usual synchronous type with polyphase windings in the stator. The rotor has permanent magnet segments arranged on the surface of a solid iron core. A carbon fibre bandage around the permanent magnets gives the rotor sufficient strength at high speed. A cross-section of the four-pole generator is shown in Fig. 1 .

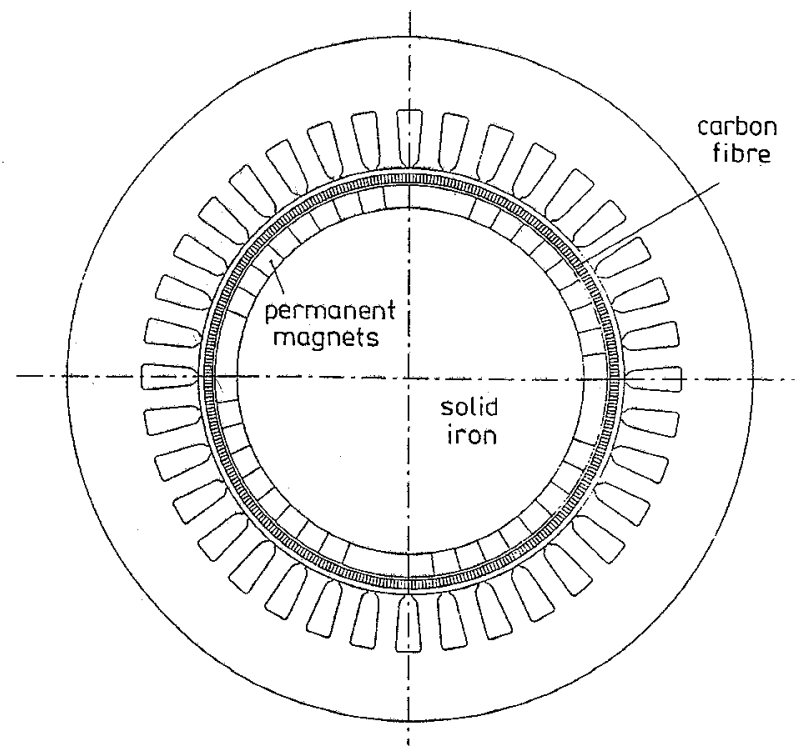

Fig. 1 Outline of the construction of the high-speed generator

For high power at high speed the power density should be as high as possible. The maximum admissible circumferential speed of the rotor and the possible diameter-to-length ratio set a limit to the dimensions. Consequently, it is difficult to cool the compact construction to a tolerable temperature level. A choice has been made for a liquid cooling system. Therefore, special attention should be paid to the prediction of the losses and it is necessary to find ways to decrease the losses by an adequate construction.

The application of the construction as given in Fig. 1, generally available for a power up to $20 \mathrm{~kW}$ and a speed of $6000 \mathrm{rpm}$, for a $1400 \mathrm{~kW}$ generator would cause two problems; the inductance will be too high for commutation of a rectifier load at rated power and the asynchronous components in the air-gap field will induce eddy currents in the solid rotor iron. The eddy current losses can exceed the limit set by cooling capacity and acceptable temperature rise.

A conducting layer around the permanent magnets of the rotor offers a solution to both problems. A good conducting shield will have lower eddy current losses due to asynchronous field components than the solid rotor iron. The idea of a conducting shield in the rotor goes back to at least the times when alternatives with superconducting field windings were considered [3]. The conducting shield had two purposes; damping of mechanical oscillations and screening of an inverse field component. It also decreases the subtransient reactance, which facilitates commutation.
A further reduction of the rotor losses is possible with the use of a modified polyphase system in the stator circuit. The stator coils can be divided in several subsystems with a regular displacement in space. In this way the number of possible asynchronous components in the air-gap field will decrease. This will ultimately result in a loss reduction.

The following Sections deal with an analysis of possible air-gap field components, the losses caused by such components and a comparison of the rotor losses for several configurations of the stator windings with and without rotor shielding.

\section{Harmonic field components}

\subsection{Three-phase winding}

In an electrical machine the effects of a nonsinusoidal current and a nonsinusoidal distribution of the windings can be described with Fourier series of the current in time and of the winding distribution in space [4]. First the well known case of a three-phase winding will be treated. In a machine with pole pair number $p$ and a phase current with angular frequency $\omega_{s}$ each phase will have a shift in space of $2 \pi / 3 p$ and the phase current a shift in time of $2 \pi / 3 \omega_{s}$. With $n$ as the order of the harmonics in the current and $q$ as the order of the harmonics in space, relative to the pole pair number, the surface current density at the stator bore can be written as

$$
\begin{aligned}
A_{n, q}= & I_{n} Z_{q} \frac{1}{2} \\
& \times \sum_{i=1}^{3} \cos \left[n \omega_{s} t-q p \theta_{s}-(n-q)(i-1) \frac{2 \pi}{3}\right] \\
& +\cos \left[n \omega_{s} t+q p \theta_{s}-(n+q)(i-1) \frac{2 \pi}{3}\right]
\end{aligned}
$$

With $(n-q)=\ldots-9,-6,-3,0,3,6,9, \ldots$ eqn. 1 becomes

$$
A_{n, q}=\frac{3}{2} I_{n} Z_{q} \cos \left(n \omega_{s} t-q p \theta_{s}\right)
$$

and these components have a positive angular velocity $n \omega_{s} / q p$. With $(n+q)=\ldots 3,6,9, \ldots$ eqn. 1 becomes

$$
A_{n, q}=\frac{3}{2} I_{n} Z_{q} \cos \left(n \omega_{s} t+q p \theta_{s}\right)
$$

and these components have a negative angular velocity $-n \omega_{s} / q p$. Other combinations of $n$ and $q$ do not have a resulting current density component.

As most of these field components do not run synchronously with the rotor the elimination of these asynchronous components might improve the behaviour of the machine. The next measures will in a simple way eliminate a lot of these components.

First, make the windings symmetrical in space so that the space distribution of the windings becomes $Z\left(p \theta_{s}\right)$ $=-Z\left(p \theta_{s}-\pi\right)$ and only odd harmonics exist. Secondly, make the sum of the stator phase currents

$$
\sum_{i=1}^{3} I_{s_{i}}=0
$$

components with order $n=3,6,9, \ldots$ become zero Thirdly, make the electrical load symmetric with $I_{s}\left(\omega_{s} t\right)$ $=-I_{s}\left(\omega_{s} t-\pi\right)$, so only odd harmonics will exist.

As a result the remaining harmonics have the order $n$ $=6 k_{1} \pm 1$ and $q=2 k_{2}-1$, with $k_{1}=1,2,3, \ldots$ and 
$k_{2}=1,2,3 \ldots$. Only combinations with $|n-q|=0,6$, $12, \ldots$ and $n+q=6,12,18, \ldots$ remain.

In the following calculations it will be taken for granted that the three aforementioned conditions have been fulfilled.

\subsection{Transformation to rotor co-ordinates}

For the calculation of the losses in the rotor a transformation to rotor co-ordinates is necessary. The transformation is carried out with

$$
\theta_{r}=\theta_{s}-\omega_{m} t
$$

and

$$
p \omega_{m}=\omega_{s}
$$

With $|n-q|=0,6,12, \ldots$ the transformation of eqn. 2 results in

$$
A_{n, q}=\frac{3}{2} I_{n} Z_{q} \cos \left[(n-q) \omega_{s} t-q p \theta_{r}\right]
$$

Components with $n-q=0$ run synchronously with the rotor and contribute to the torque. Components with $\mid n$ $-q \mid=6,12,18, \ldots$ cause rotating fields with rotor frequencies $(n-q) \omega_{s}$ and pole pair number $p q$, relative to the rotor.

With $n+q=6,12,18, \ldots$ the transformation of eqn. 3 yields

$$
A_{n, q}=\frac{3}{2} I_{n} Z_{q} \cos \left[(n+q) \omega_{s} t+q p \theta_{r}\right]
$$

These components have a rotor frequency $(n+q) \omega_{s}$ and pole pair number $p q$, relative to the rotor.

As a result; the rotor frequencies of the asynchronous field components are multiples of $\pm 6 k_{3} \omega_{s}$.

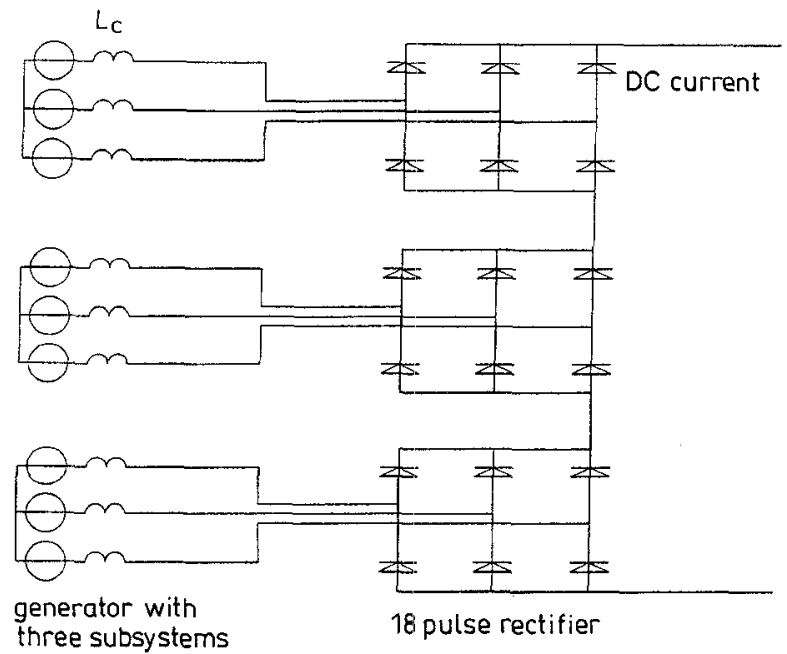

Fig.2 Generator with three subsystems and 18-pulse rectifier $L_{c}=$ commutation inductivity

\subsection{Division of the stator windings in subsystems}

One phase winding of a three-phase winding occupies $\pi / 3 p$ radians in space. A subdivision of each phase of the three-phase system in $k$ parts, which have a shift in space of $\pi / 3 p k$, makes it possible to realise $k$ threephase subsystems with a shift in time of $\pi / 3 \omega_{s} \mathrm{k}$ for the currents. To make the subsystems as symmetrical as possible the subsystems can be connected as given in Fig. 2 for $k=3$. Each subsystem is star-connected and the DC sides of the rectifiers are in series, so the current in each subsystem has the same magnitude. The rectifier is 18-pulse for $k=3$.
The classic DC machine demonstrates the usefulness of a polyphase system. Each armature coil can be considered as one phase, with a nonsinewave current and winding distribution. Nearly all resulting field components have the same speed relative to the armature (or, at standstill, relative to the brushes).

The stator current density follows from the sum of the $k$ three-phase subsystems

$$
\begin{aligned}
A_{n, q}= & \frac{3}{2} I_{n} Z_{q} \\
& \times \sum_{j=1}^{k} \cos \left[n \omega_{s} t-q p \theta_{s}-\frac{(n-q)(j-1) \pi}{3 k}\right] \\
& +\cos \left[n \omega_{s} t+q p \theta_{s}-\frac{(n+q)(j-1) \pi}{3 k}\right]
\end{aligned}
$$

For each subsystem the first term in eqn. 7 differs from zero for $|n-q|=0,6,12, \ldots$ and the second term of eqn. 7 differs from zero for $n+q=6,12,18 \ldots$.

For the whole system the result is

$$
A_{n, q}=\frac{3 k}{2} I_{n} Z_{q} \cos \left(n \omega_{s} t-q p \theta_{s}\right)
$$

for $|n-q|=0,6 k, 12 k, \ldots$ and

$$
A_{n, q}=\frac{3 k}{2} I_{n} Z_{q} \cos \left(n \omega_{s} t+q p \theta_{s}\right)
$$

for $n+q=6 k, 12 k, 18 k, \ldots$.

In this way many combinations of $n$ and $q$ do not have a resulting current density. Of course one has to keep in mind that the distribution of the subsystems might be different from the distribution of the undivided three-phase windings.

The transformation to rotor co-ordinates with eqns. $4 a$ and $b$ yields synchronous components with frequency zero and pole pair number $p q$ for $n-q=0$, asynchronous components with frequency $(n-q) \omega_{s}$ and pole pair number $p q$ for $|n-q|=6 k, 12 k, \ldots$ and asynchronous components with frequency $(n+q) \omega_{s}$ and pole pair number $p q$ for $n+q=6 k, 12 k, 18 k, \ldots$.

The comparison of a regular nine-phase system with a $3 \times 3$-system (a three-phase system with $k=3$ subsystems) shows that the $3 \times 3$-system is a modified ninephase system. The main property of a $3 \times 3$-system (with three separate star connections) is that $I_{n}=0$ for $n=3,6,9, \ldots$. A nine-phase system is characterised by $I_{n}=0$ for $n=9,18,27, \ldots$.

The description of a $2 \times 3$-phase [5] or 6-phase [6] system gives an incomplete condition for the elimination of harmonic components. The expected decrease in rotor losses is not specified.

\section{Rotor losses}

\subsection{Approximate solution of the field equations}

The calculation of the rotor losses can be done in several ways. For instance by treating the conducting parts of the rotor as discrete circuits for each space harmonic and by finding the dissipation from a solution of the equivalent circuit equations. One only needs to find the frequency-dependent circuit parameters from the field equations, but only approximations are possible because of the conducting solid iron core and the end effects. The losses can also be found from an exact solution of the field equations in the two-dimensional case $[7,8]$ and a calculation of the end effects is 
possible for low frequencies and conductivities [9]. The main subject of this study however is the high-frequency and conductivity case. So, it seems easier to start with an approximation that at least includes the effects of material properties, dimensions and harmonics. Besides, the large air gap makes the slot ripple effect [10], i.e. induction variations caused by permeance variations, small.

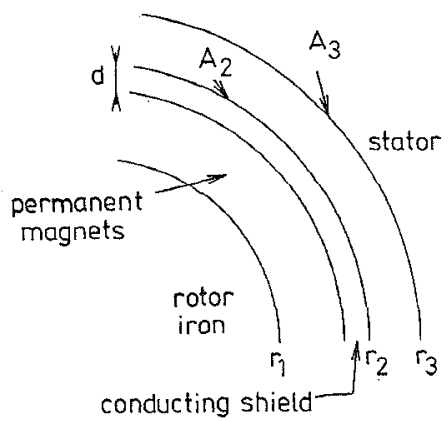

Fig.3 Rotor with conducting shield

First the losses caused by one component of the stator current density $A_{3}$ with pole pair number $p q$ and frequency $n \omega_{s}$ are calculated. Around the permanent magnets on the solid iron is a thin conducting shield with thickness $d$ and conductivity $s$ (Fig. 3). The magnet poles with height $h_{m}$ are not drawn in Fig. 3. The stator bore is assumed to be a cylinder (without slots) with a surface current density $A_{3}$ at radius $r_{3}$. The induced current in the rotor has a surface current density $A_{r g}$.

The field equations for the air gap are

$$
\nabla \cdot \mathbf{B}=0
$$

and as the volume current density in the air gap equals zero

$$
\nabla \times \mathbf{H}=0
$$

with the two-dimensional solution in polar co-ordinates [11]

$$
\begin{aligned}
& B_{\theta}=\left[C_{1}\left(\frac{r}{r_{0}}\right)^{p q-1}+C_{2}\left(\frac{r_{0}}{r}\right)^{p q+1}\right] \cos (p q \theta+\phi) \\
& B_{r}=\left[C_{1}\left(\frac{r}{r_{0}}\right)^{p q-1}-C_{2}\left(\frac{r_{0}}{r}\right)^{p q+1}\right] \sin (p q \theta+\phi)
\end{aligned}
$$

The radius $r_{0}$ which can be freely chosen, will have the value $r_{0}=r_{3}$.

The integration constants $C_{1}$ and $C_{2}$ can be found when the boundary conditions are known.

At the stator bore

$$
\lim _{r \rightarrow r_{3}} H(\theta)=A_{3}(\theta)=\hat{A}_{3} \cos p q \theta
$$

for an arbitrarily chosen space harmonic with order $q$ and with $A_{3}$ as the surface current density at the stator bore. The phase angle $\phi$ is set to zero as losses do not depend on the phase of the current.

For the rotor, two cases will be treated:

(a) With a conducting shield in the rotor around the permanent magnets at radius $r_{2}$ the rotor currents will flow in a conducting layer at radius $r_{g}=r_{2}$. The assumption is perfect screening (the limit value for high frequency and/or conductivity) and by consequence the boundary condition is

$$
\lim _{r \rightarrow r_{g}} B_{r}=0
$$

(b) Without a conducting shield on the rotor the assumption is that the eddy currents in the solid iron will flow in a very thin layer at radius $r_{g}=r_{1}$. The eddy currents in the permanent magnet segments can be made arbitrarily small by making the segments small. These eddy currents will not shield the solid iron core for the space harmonics of low order because the small segments are not connected. The space harmonics with high-order $q$ will decrease very fast with decreasing $r$ and the contribution to the rotor losses will be low for these high-order harmonics. The boundary condition for the solid iron rotor core is

$$
\lim _{r \rightarrow r_{g}} B_{r}=0
$$

The high rotor speed and the division of the stator windings in subsystems with $k>1$ make the assumption of perfect screening reasonable: high $\omega_{m}, \omega_{s}=p \omega_{m}$ and $\omega_{r}$ is (a multiple of) $6 k \omega_{s}$.

The surface current density at radius $r_{g}$ can now be found. Combination of eqns. 15 and 13 gives

$$
C_{1}=C_{2}\left(\frac{r_{3}}{r_{g}}\right)^{2 p q}
$$

Combining eqns. 14 and 12 yields

$$
C_{1}+C_{2}=\hat{A}_{3} \mu_{0}
$$

As a result the integration constants become

$$
C_{1}=\hat{A}_{3} \frac{\mu_{0}}{1+\left(\frac{r_{g}}{r_{3}}\right)^{2 p q}}
$$

and

$$
C_{2}=\hat{A}_{3} \frac{\mu_{0}}{1+\left(\frac{r_{3}}{r_{g}}\right)^{2 p q}}
$$

The field solution at radius $r_{g}$ is

$$
\begin{aligned}
B_{\theta}= & \hat{A}_{3} \mu_{0} \frac{1}{1+\left(\frac{r_{g}}{r_{3}}\right)^{2 p q}} \\
& \times\left[\left(\frac{r_{g}}{r_{3}}\right)^{p q-1}+\left(\frac{r_{g}}{r_{3}}\right)^{2 p q}\left(\frac{r_{3}}{r_{g}}\right)^{p q+1}\right] \cos p q \theta
\end{aligned}
$$

or

$$
\hat{B}_{\theta}=\hat{A}_{3} \mu_{0} \frac{2\left(\frac{r_{g}}{r_{3}}\right)^{p q-1}}{1+\left(\frac{r_{g}}{r_{3}}\right)^{2 p q}}
$$

and the relation between the current density $\hat{A}_{3}$ at the stator bore and the current density $\hat{A}_{r g}$ in the conducting layer is

$$
\hat{A}_{r_{g}}=\hat{H}_{\theta}=\hat{A}_{3} \frac{2\left(\frac{r_{g}}{r_{3}}\right)^{p q-1}}{1+\left(\frac{r_{g}}{r_{3}}\right)^{2 p q}}
$$

From this surface current density follows the volume current density

$$
J_{r_{g}}=\frac{A_{r_{g}}}{d_{g}}
$$


for a thin layer with thickness $d_{g}$. For a conducting shield at radius $r_{g}=r_{2}, d_{g}$ equals the thickness $d$ of the conducting shield at low frequencies. At high frequencies the skin effect can be taken into account by using

$$
d_{g}=d_{\text {skin }}=\sqrt{\frac{2}{\omega_{r} \sigma \mu_{r} \mu_{0}}}
$$

\subsection{Losses}

The conducting losses $P_{r_{g}}$ in the conducting layer at radius $r_{g}$ and thickness $d_{g}^{g}$ are calculated over the conducting volume and one period of time

$$
P_{r_{g}}=\frac{\omega_{r}}{2 \pi} \int_{0}^{2 \pi / \omega_{r}} \int_{0}^{l} \int_{0}^{2 \pi} \int_{r_{g}-d_{g} / 2}^{2 \pi} J_{r_{g}}^{2} / \sigma d r r d \theta d z d t
$$

As the average of the square of a sine or cosine over one period equals $1 / 2$ the losses from one component of the eddy currents becomes

$$
P_{r_{g}}=\frac{\pi r_{g} l}{\sigma d_{g}} \hat{A}_{r_{g}}^{2}
$$

for $d_{g} \ll<r_{g}$. The total losses $P_{r}$ caused by the induced currents in the rotor shield can be obtained by summation of the losses of the relevant components. The square of the total current density should be used in the above integral but as the crossproducts of components with different pole pair number, frequency or velocity have an average value equal to zero, the sum of the squares is sufficient.

\subsection{Quality factor}

The main assumption in the calculation of the rotor losses is the boundary condition (eqn. 15) which depends on the conductivity of the shield. As a test a quality factor can be used.

The currents in the rotor shield are induced by an electric field originating from the asynchronous field components of the stator currents. The electric field strength at radius $r_{2}$, when the shield is absent, follows from $E=v \times B$

$$
P_{r_{g}}=\frac{\pi r_{g} l}{\sigma d_{g}} \hat{A}_{r_{g}}^{2}
$$

The magnetic induction at radius $r_{2}$ follows from eqns. 12 and 13 with boundary condition (eqn. 14) at the stator bore and $B_{r}=0$ at radius $r_{1}$ of the solid iron core

$$
\hat{B}_{2}=\hat{A}_{3} \mu_{0}\left(\frac{r_{2}}{r_{3}}\right)^{p q-1} \frac{1-\left(\frac{r_{1}}{r_{2}}\right)^{2 p q}}{1+\left(\frac{r_{1}}{r_{3}}\right)^{2 p q}}
$$

For a conducting shield at $r_{g}=r_{2}$ a quality factor $Q_{s, n, q}$ can be defined as

$$
Q_{s, n, q}=\frac{\hat{E}_{2}}{\frac{\hat{J}_{2}}{\sigma}}
$$

The current density $\hat{J}_{2}$ follows from eqn. 24 with $r_{g}=$ $r_{2}$. It should be noted that the approximation $B_{r}=0$ at the solid iron surface with radius $r=r_{1}$ results in too small values of $\hat{B}_{2}, \hat{E}_{2}$ and $Q_{s, n, q}$ at low rotor frequencies.

The analogy with an equivalent short-circuited rotor winding helps with the interpretation. For low values of $Q_{s, n, q}$ (smaller than 1) there is no shielding of the asynchronous field components but mainly a phase shift. $Q_{s, n, q}=1$ marks the $3 \mathrm{~dB}$ point for the dissipation in the shield and the field within the shield. For high values of $Q_{s, n, q}$ the shield behaves as an inductive circuit with excellent shielding of the asynchronous field components. At high frequencies however, when the skin depth in the shield becomes important $\left(d_{\text {skin }}<d\right)$, the approximation with one equivalent short-circuited rotor circuit is no longer valid.

When there is no conducting shield around the permanent magnets the rotor losses in the solid iron core can be estimated using eqn. 27 , but a simple check with a quality factor is not possible.

\section{Winding distribution and current waveforms}

4.1 Surface current density at the stator bore The usual three-phase stator winding is characterised by $k=1$ : one phase is distributed over three adjacent slots per pole; the winding has a star connection. The 3 $\times 3$-phase winding has $k=3$ : one phase per slot per pole; each subsystem has its own star connection.

The order $n$ of the harmonics in the stator current can only be odd because of a balanced load by a full bridge rectifier. The components of the stator current are zero if $n$ equals (a multiple of) 3. Asynchronous components exist if $|n \pm q|=6 k, 12 k, 18 k, \ldots$ and the resulting rotor currents have a rotor frequency $\omega_{2}=\mid n$ $\pm q \mid \omega_{s}$ with $\omega_{s}$ as the fundamental frequency of the stator currents. The surface current density $\hat{A}_{3}$ at the stator bore equals

$$
\hat{A}_{3}=\frac{3 k}{2} \hat{Z}_{q} \hat{I}_{n}
$$

with $\hat{I}_{n}$ the amplitude of the $n$th harmonic of the stator current and $\hat{Z}_{q}$ the winding distribution density for the $q$ th space harmonic of a stator phase winding.

\subsection{Winding distribution density of the space harmonics}

With the use of a Dirac function for a full pitch winding the space harmonics of a three-phase winding can be found. For the $3 \times 3$-phase system with one phase winding per pole per slot

$$
\hat{Z}_{q}=\frac{2 p}{\pi r_{3}}
$$

For the three-phase system with three windings per pole in three adjacent slots and the co-ordinate axis in the middle slot, the distribution density equals

$$
\hat{Z}_{q}=\frac{2 p}{\pi r_{3}}\left[1+2 \cos \left(q \frac{\pi}{9}\right)\right]
$$

\subsection{Harmonics of the stator currents}

If the commutation time of the stator current is neglectable a harmonic with order $n$ has the amplitude

$$
\hat{I}_{n}=\frac{2 \sqrt{3}}{n \pi} I_{d c}
$$

In case the commutation time has to be taken into account, an approximation with linear commutation during an interval $m$ can be used

$$
\hat{I}_{n}=\frac{2 \sqrt{3}}{n \pi} \frac{\sin \left(n \frac{\mu}{2}\right)}{n \frac{\mu}{2}} I_{d c}
$$

\section{Numerical calculations}

\subsection{Calculations}

The rotor losses have been calculated for two winding configurations of the synchronous generator; the first 
with the usual three-phase winding, the second with a 3 $\times 3$-phase winding. For both winding configurations the calculations are carried out with and without a copper shield around the permanent magnets on the rotor to demonstrate the effect of shielding.

The amplitude of all eddy current components in the rotor shield or at the surface of the solid iron when there is no shield and no shielding by the segmented permanent magnets follows from eqn. 23

$$
\hat{A}_{r_{g}}=\hat{A}_{3} \frac{2\left(\frac{r_{g}}{r_{3}}\right)^{p q-1}}{1+\left(\frac{r_{g}}{r_{3}}\right)^{2 p q}}
$$

with $r_{g}=r_{2}$ for a conducting shield or $r_{g}=r_{1}$ for the solid iron in the absence of a shield.

The calculations have been carried out for a fourpole, $18000 \mathrm{rpm}, 1400 \mathrm{~kW}$ generator. The stator frequency equals $600 \mathrm{~Hz}$ and the rotor frequency (in the case of a $3 \times 3$-phase system) is (a multiple of) $10800 \mathrm{~Hz}$.

The calculations have been done for the stator current at full load, for several configurations:

(a) with conducting shield and perfect shielding; only the shield will have eddy current losses by asynchronous components of the stator field

(b) without conducting shield and no influence of the conducting permanent magnet segments; the rotor losses will be concentrated in the solid iron

(c) a three-phase winding with one phase in three adjacent slots (of the 9) per pole and six-pulse rectifier

(d) a $3 \times 3$-phase winding with one phase per slot (of the 9) per pole and 18-pulse rectifier

(e) a $4 \times 3$-phase winding with one phase per slot (of the 12) per pole and 24-pulse rectifier.

In most cases the skin depth is less than the thickness of the conducting shield and this value is used for the loss calculation. The commutation time of the stator current has been taken as zero.

A two-dimensional finite-element calculation has been done for an air-gap winding at the stator bore with $n=17, q=1$, frequency $10800 \mathrm{~Hz}$ and $I_{d c}=969 \mathrm{~A}$. The shielding effect can be seen in Fig. 4. The finiteelement calculation and the approximate solution (eqn. 27) gave the same (rounded) value of $57 \mathrm{~W}$ for the losses.

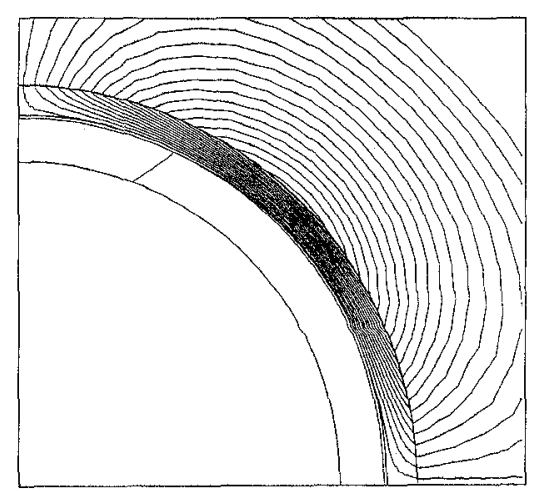

Fig. 4 Flux lines for $n=17$ and $q=1$ in case of a conducting shield around the rotor

Units: length: METR; flux density: TESL; field strength: AM; potential: WBM conductivity: SM: source density: AMZ; power: WATT force: NEWT; energy: JOUL: mass: $K G$

Problem data: verln 17q 1 ac; linear elements; $\mathrm{XY}$ symmetry; vector potential. magnetic fields; $\mathrm{AC}$ solution; frequency $=10800.0 ; 2767$ elements; 1467 nodes; 10 regions; 10 symm pairs

\subsection{Calculation results}

The calculations have been limited to harmonics of orders $1-25$ for both $n$ and $q$. In this way two important combinations are included:

(a) the slot harmonics and the fundamental of the stator current

(b) the harmonics in the stator current and the fundamental in space.

The results of the loss calculations are listed in Table 1. The value of the rotor losses $(88 \mathrm{~kW})$ for the usual three-phase winding without a conducting shield in the rotor is unacceptably high. The cooling capacity of the liquid cooling system is about $2 \mathrm{~kW}$.

\section{Table 1: Calculation results}

\begin{tabular}{|c|c|c|c|c|}
\hline Type & Description & $I_{d c}(\mathrm{~A})$ & $P_{r}(\mathrm{~kW})$ & $Q_{s_{r} n, q}$ \\
\hline 1 & $\begin{array}{l}3 \text { phases } \\
3 \text { slots / pole / phase } \\
\text { no shield }\end{array}$ & 969 & 88 & not relevant \\
\hline $1 a$ & $\begin{array}{l}3 \text { phases } \\
3 \text { slots / pole / phase } \\
\text { with shield }\end{array}$ & 969 & 2.1 & $\begin{array}{l}7 \\
(n=1, q=7) \\
23 \\
(n=7, q=1)\end{array}$ \\
\hline 2 & $\begin{array}{l}3 \times 3 \text { phases } \\
1 \text { slot / pole / phase } \\
\text { no shield }\end{array}$ & 969 & 11 & not relevant \\
\hline $2 a$ & $\begin{array}{l}3 \times 3 \text { phases } \\
1 \text { slot / pole / phase } \\
\text { with shield }\end{array}$ & 969 & 0.9 & $\begin{array}{l}5 \\
(n=1, q=19) \\
47 \\
(n=19, q=1)\end{array}$ \\
\hline 3 & $\begin{array}{l}4 \times 3 \text { phases } \\
1 \text { slot } / \text { pole } / \text { phase } \\
\text { with shield }\end{array}$ & 726 & 0.3 & $\begin{array}{l}4 \\
(n=1, q=25) \\
54 \\
(n=25, q=1)\end{array}$ \\
\hline
\end{tabular}

The use of a conducting shield will decrease the rotor losses to about $2 \mathrm{~kW}$. The subdivision of the stator winding in $3 \times 3$ phases results also in smaller rotor losses $(11 \mathrm{~kW})$. The best result can be obtained with a combination of subsystems in the stator windings and a conducting shield in the rotor, resulting in a loss of $0.9 \mathrm{~kW}$

The calculations do not take into account the effect of the rise time of the current (about $30^{\circ}$ at rated load). Inclusion of this effect would result in smaller values of the rotor losses. However, the unavoidable asymmetries in the geometry and in the phase currents as well as the ripple in the DC current will increase the rotor losses. End effects in the rotor might also cause an increase of the rotor losses, especially for components with small $q$. The current path in the rotor will close at the axial ends of the rotor, and for small $q$ and high $n$ this might be relatively long and narrow. Three-dimensional finite-element calculations and/or measurements are necessary for an evaluation of the end effects. A measurement was done on a copper cylinder in a rotating four-pole field [12]. Separating the two-dimensional effect from the end effect gave a result within $10 \%$ of the predicted value for the eddy current loss.

\section{Conclusions}

The combination of a conducting shield in the rotor, around the permanent magnets and the solid rotor iron, and the subdivision of the three-phase stator winding in several three-phase subsystems makes it possible to reduce the rotor losses to an acceptable 
level, e.g $0.1-0.2 \%$ of the rated power. Consequently, the cooling of the rotor to an acceptable temperature level is feasible.

An evalution of the end effects with three-dimensional finite-element simulation and/or measurements is still advisable.

\section{Acknowledgments}

The authors are grateful to NOVEM for financing this project.

\section{References}

1 KERKENAAR, R.: 'An electromechanical preliminary design of a $500 \mathrm{~kW}, 25000 \mathrm{rpm}$ generator'. Interim report EMV 93-10 of the NOVEM project, 1993 (in Dutch)

2 OFFRINGA, L.: "Perspectives of a high speed generator for a $1400 \mathrm{~kW}$ gas turbine'. Interim report of the NOVEM project, 1994 (in Dutch)

3 APPLETON, A.D., and ANDERSON, A.F.: 'A review of the critical aspects of superconducting AC generators'. Applied superconductivity conference, Anapolis, Maryland, USA, 1972, pp. $136-144$

4 KOSTENKO, M., and PIOTROVSKY, L.: 'Electrical machines' (MIR Publishers, Moscow, 1973), Vol. 2
5 BISSIG, H., and REICHERT, K.: 'The $2 \times 3$-phase converter fed synchronous machine-modelling, simulation and practical results'. International conference on the Evolution and modern aspects of synchronous machines, SM100, Zürich, Switzerland, 1991, Vol. 1, pp. $320-326$

6 BUNZIG, E., and MÜLLER, G.: 'General analysis of 6-phase synchronous machine'. International conference on the Evolution and modern aspects of synchronous machines, SM100, Zürich, Switzerland, 1991, Vol. 1, pp. 333-340

7 LIU, Z.J., BINNS, K.J., and LOW, T.S.: 'Analysis of eddy current and thermal problems in permanent magnet machines with radial-field topologies', IEEE Trans., 1995, M-31, (3), pp. 1912 1915

8 BERNOT, F., KAUFFMAN, J.M., and GUICHET, M.T.: "Computation of magnetic flux density and iron losses by Fourier-Bessel and Fourier-Laurent series in an electromagnetic vibration damper', IEE Proc. B, 1993, (1), pp. 18-26

9 RUSSEL, R.L., and NORSWORTHY, K.H.: 'Eddy currents and wall losses in screened-rotor induction motors', Proc. IEE, 1958 , 105, pp. $163-175$

10 TAKAHASHI, I., KOGANEZAWA, T., SU, G., and OHYAMA, K.: 'A super high speed PM motor drive system by a quasicurrent source inverter', IEEE Trans., 1994, IA-30, (3), pp. 683690

11 AlGER, P.I.: 'Induction machines: their behaviour and uses' (Gordon and Breach Science Publ., London, 1970, 2nd edn.)

12 KAMERBEEK, F.A. 'The loss in the copper damper cylinder of a high speed generator excited with permanent magnets'. MSc thesis, Department of Electrical Engineering, Eindhoven University of Technology, 1995 